\title{
Clinical concomitant benefits on pelvic floor dysfunctions after sacral neuromodulation in patients with incomplete spinal cord injury
}

\author{
G Lombardi, F Nelli, M Mencarini and G Del Popolo \\ Neuro-Urology Spinal Unit Department, Careggi University Hospital, Florence, Italy
}

\begin{abstract}
Objectives: To assess the concomitant clinical improvement in incomplete spinal cord injury patients (SCIPs) suffering from neurogenic bowel symptoms (NBSs), neurogenic lower urinary tract symptoms (NLUTSs) and neurogenic erectile dysfunction (NED) using sacral neuromodulation (SNM) for NBSs and NLUTSs.

Methods: Seventy-five SCIPs were selected. Before and during the follow-ups post-SNM, NLUTSs and NBSs were detected mainly through specific diaries. Erectile function was assessed using the International Index of Erectile Function composed of 5 questions (IIEF5). Quality of life (QoL) was measured with the Short Form 36 Health Survey questionnaire (SF-36). During the first stage, in which a permanent electrode was inserted percutaneously into the third sacral foramina and stimulated using an external generator, patients with NBSs or NLUTSs were required to improve their symptoms by at least $50 \%$ compared with baseline before proceeding to the second stage in which the generator was placed in the patient's buttock. NED patients needed to increase their IIEF5 score by at least $25 \%$ compared with baseline (evaluated initially 3 months after the second stage) in order to continue follow-up.

Results: Fourteen out of 37 subjects who manifested two functional pelvic dysfunctions at baseline maintained notable clinical improvement in two pelvic functions (median follow-up $>3$ years). Six had non-obstructive retention (NOR) and NED, six double incontinence, and two constipation with NOR. In the general and mental health domains of the SF-36, all patients improved their scores by at least 20\% compared with baseline.

Conclusions: SNM may be beneficial to selected incomplete SCIP with concomitant pelvic functional disturbances.

Spinal Cord (2011) 49, 629-636; doi:10.1038/sc.2010.176; published online 1 February 2011
\end{abstract}

Keywords: neurogenic voiding and bowel disorders; sacral neuromodulation; neurogenic erectile dysfunction; double incontinence; QoL

\section{Introduction}

Neurogenic patients often present concomitant pelvic functional disturbances and conservative treatments do not always guarantee symptom resolution. ${ }^{1}$ Recently it has been shown that incomplete spinal cord injury patients (SCIPs) make remarkable clinical improvements with sacral neuromodulation (SNM), either in neurogenic bowel symptoms (NBSs) or in neurogenic lower urinary tract symptoms (NLUTSs). ${ }^{2,3}$ Moreover, literature reports SNM's positive clinical effects on erectile function in SCIP as well. ${ }^{4}$

The aim of this study was to conduct medium and long follow-ups of SNM efficacy in SCIPs who had shown significant clinical improvement in more than one pelvic functional disturbance with a permanent SNM implant.

Correspondence: Dr G Lombardi, Neuro-Urology Spinal Unit Department, Careggi University Hospital, Largo Palagi 1-50139, Florence, Italy.

E-mail: giuseppelombardi@interfree.it

Received 17 February 2010; revised 13 November 2010; accepted 14 November 2010; published online 1 February 2011

\section{Patients and methods}

This is a retrospective study in male patients with incomplete spinal cord lesions who underwent permanent SNM implantation (Medtronic, Inc., Minneapolis, MN, USA) for NBSs and/or NLUTSs refractory to conservative therapies such as anticholinergics for urge urinary incontinence. Patients with neurogenic chronic constipation did not respond to suppositories, whereas antidiarrheal medication failed for subjects with fecal incontinence.

\section{Pre-first stage}

The American Spinal Injury Association Impairment Scale was used to classify patients according to injury severity. ${ }^{5}$

During the 7-day assessment period, patients with NLUTSs suspended their drug therapy and completed a voiding diary. At the end of this phase, urodynamic investigations including uroflowmetry, filling cystometry, and detrusor pressure/ flow studies were carried out. 
Table 1 Patient selection criteria for each pelvic function

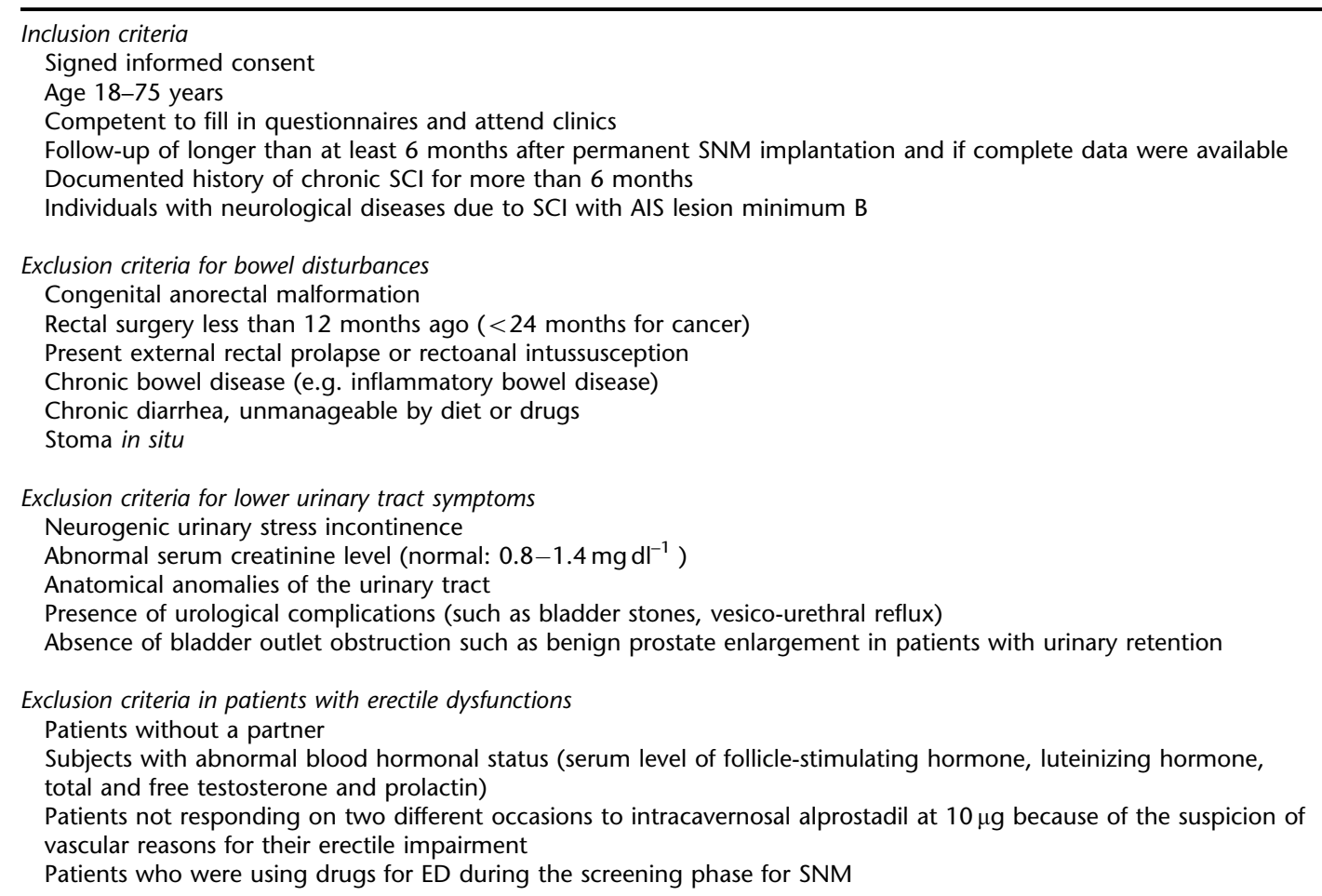

Abbreviations: AIS, The American Spinal Injury Association Impairment Scale; SCI, spinal cord injury; SNM, sacral neuromodulation.

The American Spinal Injury Association (ASIA) Impairment Scale (AIS) was used to classify patients according to injury severity.

During the 14-day assessment period, patients with NBSs suspended their NBS medication. They kept a bowel diary for 2 weeks and then underwent anorectal manometry and measurement of total gastrointestinal transit times. ${ }^{6}$

To determine erectile function, patients underwent a 14-day wash-out period and entered a 28-day assessment period during which time they attempted sexual intercourse without any treatment. Subsequently, the International Index of Erectile Function composed of 5 questions (IIEF5) was administered. ${ }^{7}$

All subjects then completed the Short Form 36 Health Survey questionnaire (SF-36) to determine the impact on health-related quality of life (QoL). ${ }^{8}$

Table 1 reports the inclusion and exclusion criteria for the first stage of SNM.

\section{First stage}

During the first stage, which lasted a minimum of 4 weeks (range 28-52 days), the permanent electrode was inserted percutaneously into the monolateral third sacral foramina and was then stimulated by using an external pulse generator (Medtronic Interstim model 3625).

To proceed to the second stage, a minimum clinical improvement of $50 \%$ in the following parameters during the first stage was mandatory: residual urine for neurogenic non-obstructive patients, urge urinary incontinence per day, number of fecal incontinence episodes per week, and, finally, the number of evacuations per week for subjects with constipation. The other clinical outcome measures for NBS and NLUTS are reported in Tables 2 and 3.

Second stage

In the second stage, a permanent implantable pulse generator was implanted in the patient's buttock. Followups for patients with NLUTSs and NBSs were scheduled at 1 , 3 and 6 months following the second stage, and then every 6 months. Before each follow-up, patients entered a 7- or 14-day assessment period for NLUTSs and NBSs, respectively, during which time they kept their diaries and abstained from symptom-related drug treatment. At the first and final visits, all patients with NLUTSs underwent urodynamics, while anorectal manometric studies were performed on subjects with NBSs. Urodynamics and anorectal manometry were executed every year on average.

The first evaluation for erectile function was done after 3 months.

Regarding erectile function, only a score equal to or higher than $25 \%$ compared with baseline indicated remarkable clinical enhancement in patients with neurogenic erectile dysfunction (NED). Only those who benefited significantly in erectile function at the first visit completed the IIEF5 every 6 months. Twenty-eight days before each follow-up, these subjects commenced an assessment period, during 
Table 2 Data on patients with neurogenic urinary tract symptoms

\begin{tabular}{|c|c|c|c|c|}
\hline $\begin{array}{l}\text { Parameters investigated in patients } \\
\text { with non-obstructive retention }\end{array}$ & Baseline & First visit post-SNM & Final visit after permanent SNM & $\begin{array}{l}\text { Median \% improvement } \\
\text { in the final visit }\end{array}$ \\
\hline \multicolumn{5}{|l|}{ Voiding diary entries } \\
\hline $\begin{array}{l}\text { Catheterized volume } \\
\text { per catheterization } \mathrm{ml}^{-1}\end{array}$ & $365 \pm 69$ (range $260-450)$ & $115 \pm 20.70$ (range $80-140)$ & $132.50 \pm 24.34$ (range $90-170)$ & 71.66 (range 63.33-79.49) \\
\hline Mean number of CSIC & $3.62 \pm 0.91$ (range $2-5$ ) & $0.75 \pm 0.46($ range $0-1)$ & $0.87 \pm 0.35($ range $0-1)$ & 73.54 (range 50-100) \\
\hline Mean urinary frequency & $1.87 \pm 2.58$ (range $0-5)$ & $7 \pm 0.75$ (range 6-8) & $7.25 \pm 0.70$ (range $6-8)$ & 98.21 (range 85.71-100) \\
\hline Mean voided volume $\mathrm{ml}^{-1}$ & $41.25 \pm 57.67$ (range $0-120)$ & $245 \pm 15.11$ (range $220-270)$ & $227.50 \pm 20.52$ (range $180-240$ ) & 70.97 (range 60-80) \\
\hline \multicolumn{5}{|c|}{ Mean follow-up period from SNM permanent implantation to final visit was 53 months } \\
\hline $\begin{array}{l}\text { Parameters investigated in patients } \\
\text { with urinary urge incontinence }\end{array}$ & Baseline & $\begin{array}{l}\text { First visit after } \\
\text { permanent SNM }\end{array}$ & $\begin{array}{l}\text { Final visit after } \\
\text { permanent SNM }\end{array}$ & $\begin{array}{l}\text { Median \% improvement } \\
\text { in the final visit }\end{array}$ \\
\hline \multicolumn{5}{|l|}{ Voiding diary } \\
\hline Mean urinary frequency & $13.83 \pm 2.50($ range $10-17)$ & $7.0 \pm 0.62$ (range 6-8) & $7.16 \pm 0.63$ (range 6-9) & 97.9 (range $87.5-100$ ) \\
\hline $\begin{array}{l}\text { Mean number of urinary } \\
\text { incontinence per day }\end{array}$ & $2.83 \pm 0.75$ (range $2-4$ ) & $0.50 \pm 0.54$ (range $0-1)$ & $0.66 \pm 0.81$ (range $0-2$ ) & 80.5 (range $50-100$ ) \\
\hline Mean voided volume $\mathrm{ml}^{-1}$ & $120 \pm 29.66$ (range $80-170)$ & $231.66 \pm 17.22$ (range $210-260$ ) & $210 \pm 15.49$ (range 15.49 ) & 69.8 (range $57.1-82.3$ ) \\
\hline Nocturia & $2.83 \pm 0.75$ (range $2-4$ ) & $0.50 \pm 0.54($ range $0-1)$ & $0.50 \pm 0.54($ range $0-1)$ & 77.8 (range $50-100$ ) \\
\hline
\end{tabular}

Abbreviations: CISC, clean intermittent self-catheterization; SNM, sacral neuromodulation.

Mean follow-up period from SNM permanent implantation to final visit was 32.6 months.

Table 3 Data on patients with neurogenic bowel symptoms

\begin{tabular}{|c|c|c|c|c|}
\hline $\begin{array}{l}\text { Parameters investigated in patients } \\
\text { with fecal incontinence }\end{array}$ & Baseline & $\begin{array}{l}\text { First visit after } \\
\text { permanent SNM }\end{array}$ & Final visit after permanent SNM & $\begin{array}{l}\text { Median \% improvement } \\
\text { in the final visit }\end{array}$ \\
\hline \multicolumn{5}{|l|}{ Bowel diary } \\
\hline $\begin{array}{l}\text { Mean number of occurrences } \\
\text { of fecal incontinence per week }\end{array}$ & $4.33 \pm 1.66($ range $2.5-7)$ & $0.91 \pm 0.97($ range $0-2.5)$ & $1.25 \pm 1.17$ (range $0-3)$ & 72.3 (range $57.1-100$ ) \\
\hline Days with pads per week & $4.50 \pm 1.51$ (range $3-7)$ & $1.16 \pm 1.16$ (range $0-3)$ & $1.33 \pm 1.16($ range $0-3)$ & 69.1 (range $50-100$ ) \\
\hline Wexner score & $13.66 \pm 1.50$ (range $11-15)$ & $4.83 \pm 0.75$ (range $4-6)$ & $5.83 \pm 0.98$ (range $5-7)$ & 58.5 (range $50-66.7$ ) \\
\hline \multicolumn{5}{|c|}{ Mean follow-up period from SNM permanent implantation to final visit was 32.6 months } \\
\hline $\begin{array}{l}\text { Parameters investigated for } \\
\text { each of the two constipation patients }\end{array}$ & Baseline & First visit post permanent SNM & Final visit post permanent SNM & $\%$ Improvement in the last visit \\
\hline \multicolumn{5}{|l|}{ Key bowel parameters } \\
\hline Number of evacuations per week & 1.5 & 5.5 & 5.0 & 63.6 \\
\hline Time per defecation $\min ^{-1}$ & 45 & 5 & 5 & 95.2 \\
\hline Wexner score & 21 & 5 & 6 & 71.4 \\
\hline \multicolumn{5}{|l|}{ Key bowel parameters } \\
\hline Number of evacuations per week & 2 & 6 & 6 & 80 \\
\hline Time per defecation $\mathrm{min}^{-1}$ & 50 & 10 & 10 & 85.1 \\
\hline Wexner score & 23 & 6 & 7 & 69.6 \\
\hline
\end{tabular}

Mean follow-up period from SNM permanent implantation to final visit was 59.5 months.

which time they attempted sexual intercourse without treatment.

Subsequently, the clinical follow-up data were reported only for SCIPs who demonstrated marked clinical improvement in two pelvic functions at the first second stage until the final visit, which took place by January 2010. The SF-36 was administered to all patients after each follow-up.

The Wilcoxon test was used to compare clinical findings on voiding, and a bowel diary was completed at baseline and during follow-ups post-permanent SNM. Additionally, the Wilcoxon test was applied comparing urodynamic and anomanometric findings at baseline and during the follow-ups after SNM implantation. The Wilcoxon test was used to compare each domain score of the SF-36 questionnaire at baseline and during follow-ups post-surgery. $\chi^{2}$-test was applied to evaluate which clinical factors were determinant in providing benefits on associated pelvic functions compared with non-responders. The study was conducted after obtaining approval from the local Ethical Committee. All participants provided written informed consent before enrollment in the study.

\section{Results}

Seventy-five patients with incomplete SCI were selected for the first stage of SNM. Thirty-seven subjects (49.3\%) showed at least two chronic functional disorders. Of those, 44 patients $(58.6 \%)$ had a lower motoneuron lesion. Sixteen patients $(43.2 \%)$ with two pelvic dysfunctions evidenced NED with a median IIEF5 score of 15.6 (range 14-18). All patients had satisfactory sexual intercourse; 14 were taking oral phosphodiesterase 5 and 3 were using intracavernous injections of prostaglandin E1.

Overall, 14 individuals (37.8\%) with two functional pelvic disturbances at baseline were selected. Following the first 


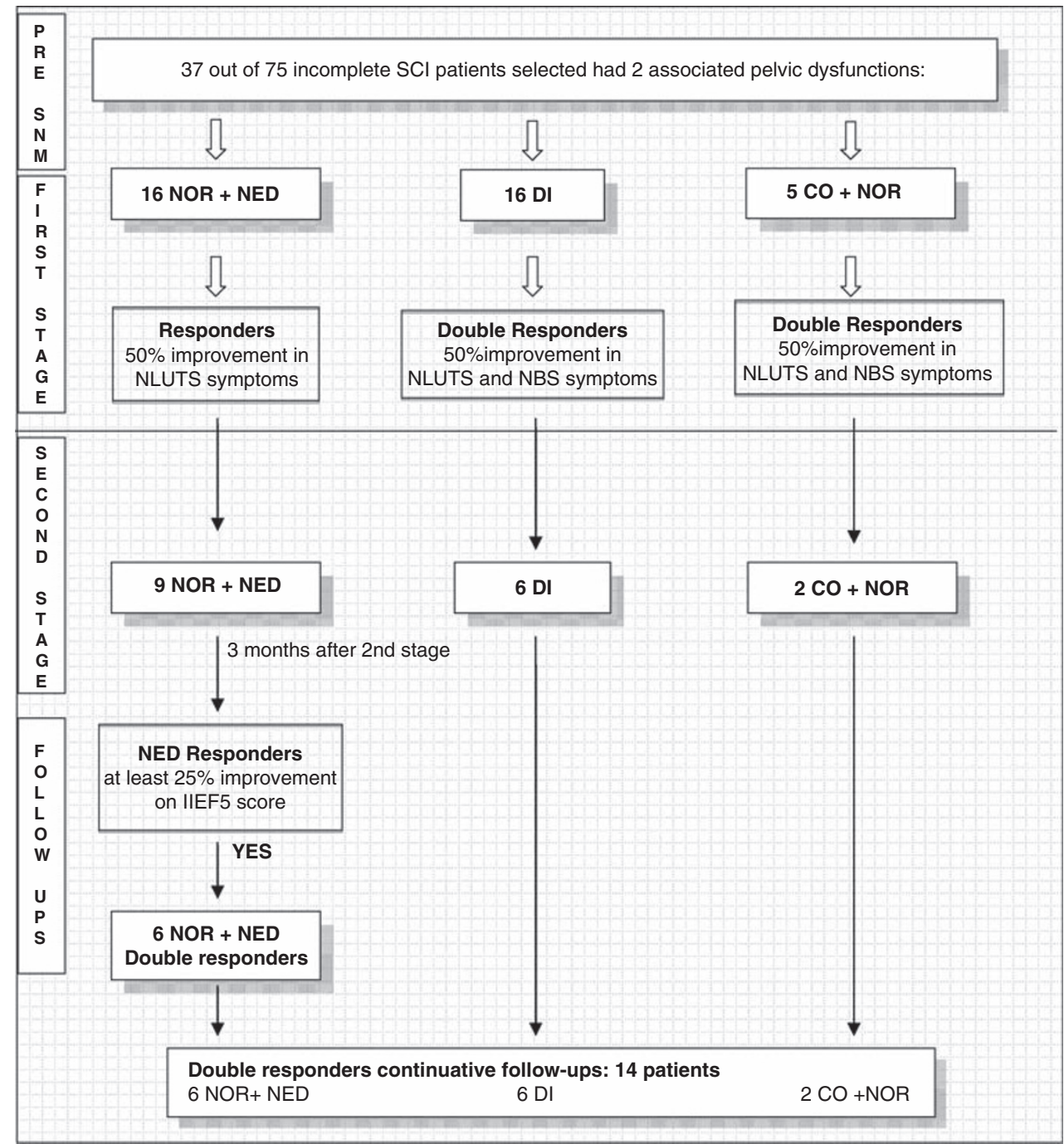

Figure 1 Study design: CO + NOR, constipation and non-obstructive retention; DI, double incontinence; NLUTSs, neurogenic lower urinary tract symptoms; NOR + NED, non-obstructive retention and neurogenic erectile dysfunction.

stage (median duration 40.5 days), 8 out of 21 SCIPs (38.1\%) with NLUTSs and NBSs participated in the second stage because their symptoms improved by at least 50\%. Moreover, 6 out of 16 patients $(37.5 \%)$ with non-obstructive retention (NOR) and NED at baseline were included, as their NOR symptoms improved by at least 50\% during the first stage, and three months after the second stage they showed at least a $25 \%$ increase in the IIEF5 score as well. Figure 1 summarizes the study.

The results are reported according to their functional pelvic disturbances.

\section{Neurogenic lower urinary tract symptoms}

Non-obstructive retention. Eight subjects with a lower motoneuron lesion suffered from NOR. Six had American Spinal Injury Association Impairment Scale $\mathrm{C}$ and two had American Spinal Injury Association Impairment Scale D. Four patients had voluntary anal contraction. Mean age was
44.2 years (range 31-62). Three out of eight patients (37.5\%) emptied per void between $90-120 \mathrm{ml}$ using the Valsalva maneuver, but with elevated post-void residual urine utilizing 2-3 catheterizations per day, whereas the others emptied their bladders exclusively with intermittent catheterization.

Pre-first-stage urodynamic findings in the voiding phase showed that five patients had acontractile detrusor and three had detrusor underactivity. During the second-stage followups, only one patient recovered a normal bladder contractility index with a score of more than $100 .{ }^{9}$

Seven patients used the Valsalva maneuver to empty their bladders, but with a vesical pressure $<70 \mathrm{~cm} \mathrm{H}_{2} \mathrm{O}$ evidenced in every videourodynamic control. No vesical ureteral reflux was ever detected. ${ }^{10-11}$

At all follow-ups, two patients did not require catheterizations for a balanced micturition, whereas the others required one catheterization per day. Figure 2 reports the median maximum uroflowmetry data at baseline, at the first visit post-second stage, and at the final visit. Table 2 shows the 

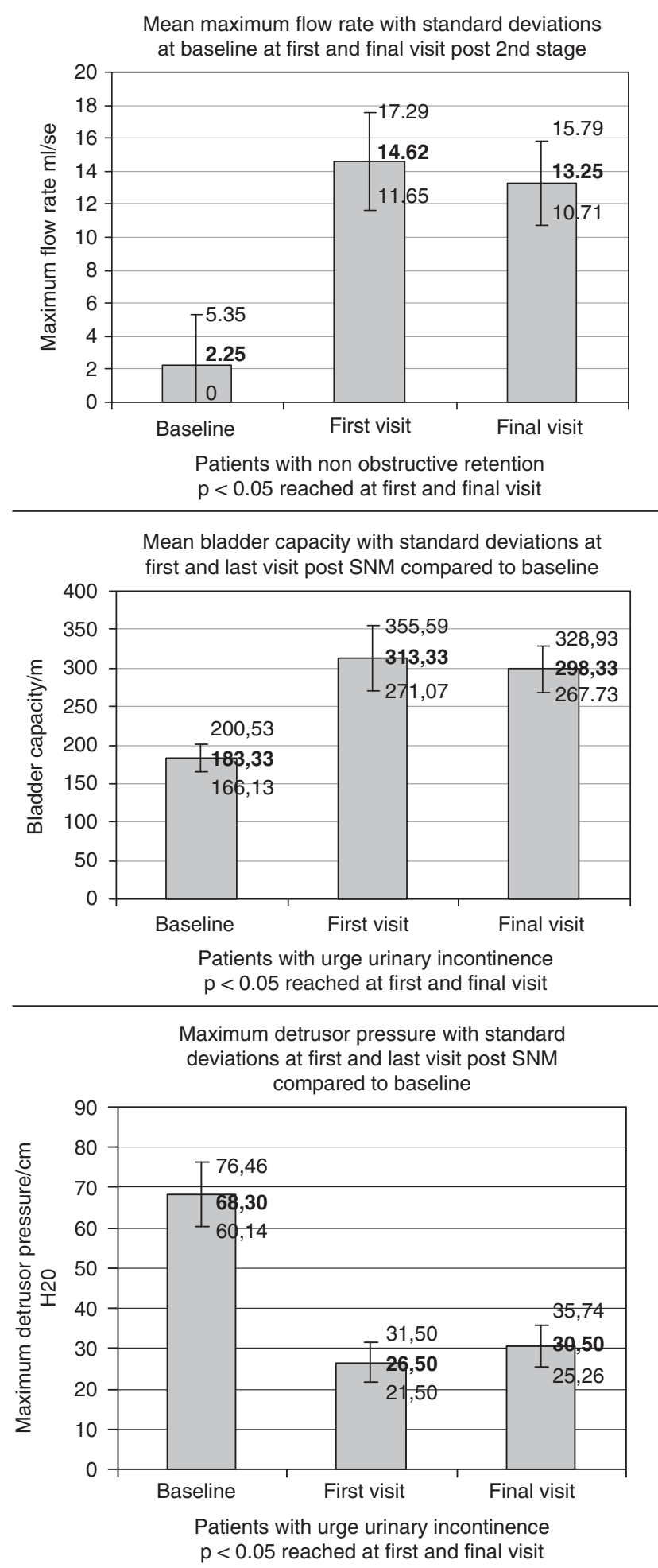

Figure 2 Urodynamic findings in patients with neurogenic lower tract symptoms.

median variation of voiding diary entries in the first visit post-second stage, and at the final visit compared with baseline.

Each patient improved by $50 \%$ compared with baseline for all the parameters investigated. A statistically significant improvement using the Wilcoxon test $(P<0.05)$ was documented at both the first and final visits post-SNM surgery for all voiding entries.

Urge urinary incontinence. Six subjects had urge urinary incontinence. Mean age was 40.5 years (range 26-54). All had upper motoneuron lesion and American Spinal Injury Association Impairment Scale C. All had voluntary anal contraction. No patient used intermittent catheterization and all emptied their bladders with a residual urine less than $50 \mathrm{ml}$. In pre-surgery urodynamics, all subjects showed neurogenic detrusor hyperactivity of various degrees during the filling phase. After the second stage, each patient improved all parameters by $50 \%$ compared with baseline, and a statistically significant improvement using the Wilcoxon test $(P<0.05)$ was documented at both the first and final visits for all voiding entries. The detrusor pressure at maximum flow rate was similar to that post-SNM compared with baseline, with a maximum value of just over $50 \mathrm{~cm} \mathrm{H}_{2} \mathrm{O}$ attained throughout the urodynamic investigation in the patient with grade I detrusor sphincter dyssynergia, according to the Blavais classification. ${ }^{12}$ Bladder capacity and maximum detrusor pressure are reported in Figure 2. During the assessment period, three patients used anticholinergics, but with lower dosages compared with baseline.

\section{Neurogenic bowel symptoms}

Urge and passive fecal incontinence. The same six patients with urge urinary incontinence had both urge and passive fecal incontinence. The mean total gastrointestinal transit time in days was 2.8. All were fully continent postpermanent SNM.

Table 3 reports the main clinical data on bowel function. Each patient improved all parameters by 50\% compared with baseline, and a statistically significant improvement using the Wilcoxon test $(P<0.05)$ was detected at both the first and final visits post-SNM surgery for all bowel diary entries recorded. Anorectal manometric findings at baseline are reported in Figure 3. After second stage, all anorectal manometric values compared with baseline shifted no more than $\pm 5 \%$.

Constipation. The two patients showed slow global transit concerning bowel function with a total gastrointestinal transit time of 3.9 and 5.2 days, respectively. One patient had voluntary anal contraction. Following the second stage, each patient showed improvement in all parameters by $50 \%$ compared with baseline, and a statistically significant improvement using the Wilcoxon test $(P<0.05)$ was detected at both the first and final visits post-SNM surgery for all bowel diary entries recorded. Table 3 reports their bowel diary entries. Figure 3 shows their anorectal manometric findings at baseline. Following the second stage, all anorectal manometric values compared with baseline changed by no more than $\pm 5 \%$.

\section{Neurogenic erectile dysfunction}

Six patients suffering from NOR also had NED. Three patients had voluntary anal contraction. Their median IIEF5 score was 15.2 (range 14-18). After the second stage, their 

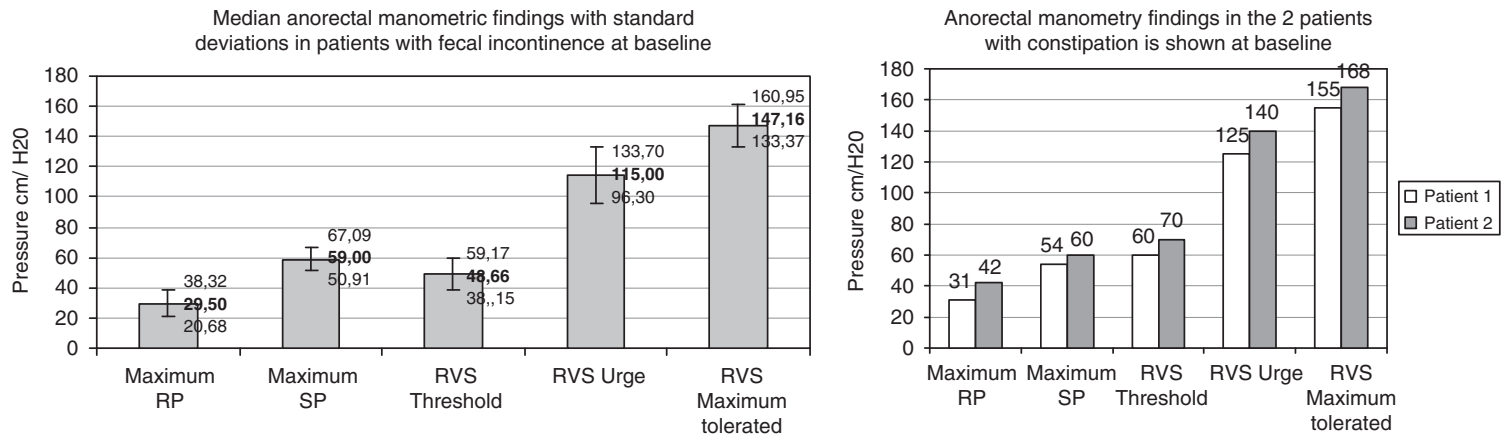

Figure 3 Anorectal manometric findings in patients with neurogenic bowel symptoms.

Table 4 Results of the six patients with erectile dysfunction at baseline

\begin{tabular}{lcccc}
\hline Erectile function & Baseline & First visit post SNM & Final visit after permanent SNM & Median \% improvement in the final visit \\
\hline IIEF5 score & $16.2 \pm 1.2$ (range 15-18) & $22.2 \pm 0.41$ (range 22-23) & $21.8 \pm 0.41$ (range 22-23) & 37.4 (range 27.7-46.6) \\
\hline
\end{tabular}

Abbreviation: IIEF5, International Index of Erectile Function composed of 5 questions.

Table 5 The SF-36 domains where a significant statistical improvement was reached throughout the entire study

\begin{tabular}{|c|c|c|c|c|c|}
\hline \multicolumn{6}{|c|}{ Median score of the SF-36 } \\
\hline Group & Domains & Baseline & First visit post-SNM & Final visit post-SNM & P-values Wilcoxon test \\
\hline \multirow[t]{4}{*}{ DI } & $\mathrm{GH}$ & 50.6 & 66.1 & 63.2 & $P<0.05^{\mathrm{a}}$ \\
\hline & SF & 49.8 & 65.1 & 63.3 & $P<0.05^{\mathrm{a}}$ \\
\hline & $\mathrm{RE}$ & 48.2 & 66.8 & 64.5 & $P<0.05^{\mathrm{a}}$ \\
\hline & $\mathrm{MH}$ & 51.8 & 65.5 & 63.6 & $P<0.05^{\mathrm{a}}$ \\
\hline \multirow[t]{2}{*}{ NOR+NED } & $\mathrm{GH}$ & 52.6 & 66.3 & 65.6 & $P<0.05^{\mathrm{a}}$ \\
\hline & $\mathrm{MH}$ & 53.8 & 67.2 & 66 & $P<0.05^{\mathrm{a}}$ \\
\hline \multirow[t]{2}{*}{$\mathrm{COST}+\mathrm{NOR}$} & $\mathrm{GH}$ & 51.5 & 65 & 66 & NA \\
\hline & $\mathrm{MH}$ & 52 & 68 & 66 & NA \\
\hline
\end{tabular}

Abbreviations: COST+NOR, constipation and non-obstructive retention; DI, double incontinence; GH, general health; $M H$, mental health; $\mathrm{NOR}+\mathrm{NED}$, non-obstructive retention and neurogenic erectile dysfunction; RE, role emotional; SF, social functioning; SNM, sacral neuromodulation.

NA: not applicable because of too few patients in this group.

${ }^{a} A$ significant statistical improvement was documented both in the first and final visit post-SNM surgery.

median score was 22. They stopped taking oral phosphodiesterase 5 inhibitors. Two patients temporarily returned to baseline clinical status with regard to voiding and erectile function after a follow-up of 38.5 months (range 29-48). Diagnosable reasons for efficacy loss were not identified. During the first-stage implant in the opposite S3 sacral root, the two subjects using the Valsalva maneuver had a residual urine volume of less than $100 \mathrm{ml}$. The median time from the new definite implant to the final visit was 40 months (range 23-57). After the new second stage, these individuals achieved and maintained an IIEF5 score of 22 and engaged in sexual intercourse without needing oral phosphodiesterase 5 inhibitors (see Table 4).

During follow-ups, none of the other eight subjects reported sexual impairments.

\section{Quality of life}

Patients were divided into three groups according to their combined symptoms: double incontinence, NOR + NED, and constipation + NOR. In all second-stage follow-ups, a significant statistical improvement in two subscales (mental and general health) of the SF-36 QoL questionnaire was observed in each group compared with baseline. Patients with double incontinence maintained a significant statistical improvement at all post-SMN follow-ups according to the Wilcoxon test $(P<0.05)$ regarding the emotional role and social functioning domains of the SF-36 (see Table 5).

\section{Complications}

Eleven drawbacks were resolved by telemetrically modifying the previous stimulation parameters. Complications were reported by dividing the patients into three groups, as was done for QoL (see Table 6).

\section{Stimulation}

The temporary external patient stimulator and permanent implantable pulse generator were both set at a frequency between 5 and $20 \mathrm{~Hz}$ and pulse width $(210 \mu \mathrm{s})$. 
Table 6 Number and type of complications for each group

\begin{tabular}{lccc}
\hline Complications & $\begin{array}{r}\text { NOR+NED } \\
3 \text { patients }\end{array}$ & $\begin{array}{c}\text { DI 2 } \\
\text { patients }\end{array}$ & $\begin{array}{c}\text { COST+NOR } \\
\text { 1 patient }\end{array}$ \\
\hline Change in stimulation sensation & 2 & 2 & 1 \\
Loss of efficacy & 2 & 0 & 0 \\
Pain per leg spasticity & 0 & 1 & 0 \\
Pain at IPG site & 1 & 1 & 0 \\
Adverse change in bowel function & 1 & 0 & 0 \\
& & & \\
Battery replacement & 2 & 1 & 0 \\
$\quad$ Number of patients & 62 & 57 & - \\
$\quad$ Mean life span of the replaced IPGs & & & \\
\hline per months & &
\end{tabular}

Abbrevation: COST+NOR, constipation and non-obstructive retention; DI, double incontinence; IPG, implanted pulse generator; NOR+NED, nonobstructive retention and neurogenic erectile dysfunction.

\section{Analysis of the failure group}

Patients were divided into two groups according to the length of time from diagnosis to SNM surgery (more or less than 3 years); a trend in non-responsiveness was detected in group 1 (duration longer than 3 years). In group 2, 11 out of 14 patients continued to the second stage versus 11 out of 23 from group $1\left(P=0.133\right.$ using $\chi^{2}$-test).

\section{Discussion}

Our experience shows that $37.8 \%$ of patients with two pelvic dysfunctions pre-SNM maintained a remarkable concomitant clinical enhancement on two pelvic functions, leading us to believe that males with incomplete SCI may be good candidates for SNM. Side effects were scarce and moderate.

One possible explanation of SNM's combined clinical benefit for NOR and NED is its action on the parasympathetic nervous system that influences both detrusor contraction and erectile function because of the fact that both reflex erection and micturition are dependent on intact sacral conus and its reflex loops. This evidence is reinforced by two patients who simultaneously lost the clinical improvement on both functions during follow-ups, and subsequently recovered after a new implant in the contralateral sacral S3 root. ${ }^{13}$ The hypothesis that increased erectile function is simply due to the improvement in urinary symptoms is difficult to support; in fact, other individuals with NED and NOR showed remarkable clinical improvement only in voiding function.

Considering NLUTS, seven out of eight patients with NOR used Valsalva maneuvers to empty their bladders; this has been urodynamically documented as safe. ${ }^{10-11}$ However, Wyndaele et al. ${ }^{10}$ also report that with increasing time, more than $40 \%$ of patients using the Valsalva maneuver showed influx into the prostate and seminal vesicles, and the bladder expression may generate reflux to the upper urinary tract.

In follow-ups longer than 4 years post-second stage, our patients never encountered these complications. Moreover, the significant reduction or abandoned use of catheterization progressively reduced the cost of the neuromodulator over time, and SNM increased their QoL.
The occurrence of late failures in NOR (25\%) due to the loss of SNM efficacy is not relevant to the selection criteria with regard to the difference between upper motoneuron versus lower motoneuron lesion patients on NLUTSs. However, these results seem to suggest that in mediumand long-term follow-ups, lower motoneuron lesion patients may have a higher risk of losing their clinical benefits because of the significant reduction or total disappearance of sensation in their perineal area, leading to the absence of perineal relaxation during their bladder expression.

Our study confirms the encouraging clinical results reported in the literature, which describe a significant improvement in bowel symptom severity of varied origins and associated with urinary disturbances. ${ }^{14-16}$

Double incontinence represents a much more severe and stressful condition of pelvic floor dysfunction. ${ }^{17}$ This explains why these patients always attained a marked statistical improvement in four domains of the SF-36 following permanent SNM. Though this is a clinical study, it is still possible to comment on ano-manometric and urodynamic findings. Some post-surgery urodynamic findings showed impressive statistical improvement.

As regards NBS, no variation was detected in ano-manometric measurements after second stage.

Anorectal findings following permanent SNM are varying and discordant in the literature. ${ }^{18,19}$ At this time, anomanometric study is not recommended for SCI patients before NBS surgeries. ${ }^{20}$ However, the utility of ano-manometric investigation either to better select SCI patients for SNM or to better comprehend SNM's mechanism of action in NBS is not yet well known.

Future research should investigate any predictable clinical factors that are correlated with the dual advantages of SNM on pelvic functions. The duration of time from neurological diagnosis to SNM therapy should be a parameter. Considering the small number of patients, larger, high-quality randomized crossover trials are needed to allow the effects of SNM on these conditions to be assessed with more certainty.

\section{Conflict of interest}

The authors declare no conflict of interest.

\section{References}

1 Benevento BT, Sipski ML. Neurogenic bladder, neurogenic bowel and sexual dysfunction in people with spinal cord injury. Phys Ther 2002; 82: 601-612.

2 Fu G, Liao LM, Lü Z, Li JJ, Wu J, Ju YH et al. Neuromodulation for treatment for neurogenic bowel dysfunction. Zhonghua Wai Ke Za Zhi 2009; 47: 128-131.

3 Lombardi G, Del Popolo G. Clinical outcome of sacral neuromodulation in incomplete spinal cord injured patients suffering from neurogenic lower urinary tract symptoms. Spinal Cord 2009; 47: 486-491.

4 Lombardi G, Mondaini N, Giubilei G, Macchiarella A, Lecconi F, Del Popolo G. Sacral neuromodulation for lower urinary tract dysfunction and impact on erectile function. J Sex Med 2008; 5: 2135-2140. 
5 American Spinal Injury Association. International Standards for Neurological and Functional Classification of Spinal Cord Injury Revised 1996. American Spinal Injury Association: Chicago, 1996.

6 Krogh K, Olsen N, Christensen P, Madsen JL, Laurbeg S. Colorectal transport during defecation in patients with lesions of the sacral spinal cord. Neurogastroenterol Motil 2003; 15: 25-31.

7 Rosen RC, Riley A, Wagner G, Osterloch IH, Kirkpatrick J, Mishra A. The international index of erectile function (IIEF): a multidimensional scale for assessment of erectile dysfunction. Urology 1997; 49: 822-830.

8 Forchheimer M, McAweeney M, Tate DG. Use of the SF-36 among persons with spinal cord injury. Am J Phys Med Rehabil 2004; 83: 390-395.

9 Abrams P. Bladder outlet obstruction index, bladder contractility index and bladder voiding efficiency: three simple indices to define bladder voiding function. BJU Int 1999; 84: 14-15.

10 Wyndaele JJ, Madersbacher H, Kovindha A. Conservative treatment of the neuropathic bladder in spinal cord injured patients. Spinal Cord 2001; 39: 294-300.

11 Madersbacher H, Wyndaele JJ, Igawa Y, Abrams P, Khoury S, Wein A. Incontinence, 2nd edn. Health Publication Ltd, UK, 1999, pp 703-708.

12 Schurch B, Schmid DM, Karsenty G, Reitz A. Can neurologic examination predict type of detrusor sphincter-dyssynergia in patients with spinal cord injury? Urology 2005; 65: 243-246.
13 Leng WW, Chancellor MB. How sacral nerve stimulation neuromodulation works. Urol Clin North Am 2005; 2: 11-18.

14 Altomare DF, Rinaldi M, Petrolino M, Monitillo V, Sallustio P, Veglia A et al. Permanent sacral nerve modulation for fecal incontinence and associated urinary disturbances. Int J Colorectal Dis 2004; 19: 203-209.

15 Jarrett ME, Mowatt G, Glazener CM, Fraser C, Nicholls RJ, Grant AM et al. Systematic review of sacral nerve stimulation for faecal incontinence and constipation. Br J Surg 2004; 91: 1559-1569.

16 Gourcerol G, Gallas S, Michot F, Denis P, Leroi AM. Sacral nerve stimulation in fecal incontinence: are there factors associated with success? Dis Colon Rectum 2007; 50: 3-12.

17 Indar A, Young-Fadok T, Cornella J. A dual benefit of sacral neuromodulation. Surg Innov 2008; 15: 219-222.

18 Kenefick NJ, Vaizey CJ, Cohen CR, Nicholls RJ, Kamm MA. Double-blind placebo-controlled crossover study of sacral nerve stimulation for idiopathic constipation. Br J Surg 2002; 89: $1570-1571$.

19 Michelsen HB, Buntzen S, Krogh K, Laurberg S. Rectal volume tolerability and anal pressures in patients with fecal incontinence treated with sacral nerve stimulation. Dis Colon Rectum 2006; 49: 1039-1044.

20 Abrams P, Andersson KE, Birder L, Brubaker L, Cardozo L, Chapple $\mathrm{C}$ et al. Evaluation and treatment of urinary incontinence, pelvic organ prolapse, and fecal incontinence. Neurourol Urodyn 2010; 29: 213-240. 